Conflicts, Competition and Social Support in Female-Dominated Vocational Education Breaking or Reaffirming Stereotypical Femininity?

Kristinn Hegna

Associate professor

Department of Education

Faculty of Educational Sciences

University of Oslo

PO box 1092, Blindern

0317 Oslo

NORWAY

Kristinn.hegna@iped.uio.no

\title{
Acknowledgements and funding
}

The author wishes to thank Ingunn Marie Eriksen and Åse Strandbu in addition to the journal's anonymous reviewers for comments on earlier versions of this article.

This work was funded by the Research Council of Norway (UTDANNING2020) within the research project 'Safety-VET. Qualification and social inclusion in upper secondary vocational education and training' [NFR Grant No. 212293] and NOVA Norwegian Social Research, where the project is hosted. 
Conflicts, Competition and Social Support in Female-Dominated Vocational Education Breaking or Reaffirming Stereotypical Femininity?

\section{Abstract (142 words)}

One in four upper secondary school students in Norway experience nearly single-sex classrooms, an unintended consequence of choosing certain vocational study programmes, such as Healthcare, childhood and youth development or Building and construction. This raises a question about how female students describe their experiences of social relationships and class room culture within the context of a gender-segregated vocational education setting. Analyses of educational biography interviews reveal that stories of conflict, competition and cultural differences dominate and are often described using derogative or gendered language, such as 'bitching', 'gossip' and 'drama'. These stories demonstrate a break with gender stereotypes but, at the same time, accentuate femininity by aligning the behaviour to stereotypical discourses of 'girl' behaviour. In their stories, gender loses its importance as a basis for solidarity and commonality when students share the same gender; instead, hierarchies and other differences become highlighted.

\section{Key words:}

Vocational education; gender segregation; gender; youth; femininity; single-sex education; discourse analysis; conflict 


\section{Conflicts, Competition and Social Support in Female-Dominated Vocational Education - Breaking or Reaffirming Stereotypical Femininity?}

Number of words: 8086 words

\section{Introduction}

Research on single-sex education tends to focus on single-sex education's effects on learning outcomes (Mael et al. 2005; Smyth 2010; Younger and Warrington 2006), with less interest in the social processes that a uni-gendered setting could evoke. Within the vocational education and training (VET) research field, male students receive relatively more attention than female students (Niemeyer and Colley 2015), and research regarding female students in VET is limited. The importance of a sense of belonging and community for learning and education completion has been well established (Markussen 2016; Osterman 2000), and female VET students in Norway complete their upper secondary education at a higher rate than their male counterparts (Markussen 2016). As such, this study's focus is to understand the processes of gender identification and social relationships through the stories of young female students in female-dominated VET programmes.

At age 16, a nearly full cohort of young people in Norway transition into upper secondary education; half of them enter into vocational education programmes. Research and public discourse have often focused on the $42 \%$ of VET students that do not complete upper secondary school within five years ${ }^{1}$. A second aspect of vocational education has received less public interest; the gender imbalance in the recruitment to vocational education programmes (cf. Haasler and Gottschall 2015). According to Statistics Norway, 30\% of male and $21 \%$ of female students in the Norwegian upper secondary education system follow one of five vocational education study programmes ${ }^{2}$ in which more than $85 \%$ of the students are the same gender (Statistics Norway 2013). This is a profound break from the lack of gender segregation in Norway's compulsory school (Wiseman 2008) and the state regulations against permanent single-sex teaching (Ministry of Education 1974, 1998). The reasoning behind the regulation is to ensure equal education for all and to promote equity, non-discrimination and unitary schooling. The background for the gender segregation in upper secondary vocational

\footnotetext{
${ }^{1}$ Compared to $14 \%$ of the general education students (Markussen 2016).

${ }^{2}$ Share of female students: Design, arts and crafts (DAC) (88.4\%), Healthcare, childhood and youth development (HCYD) (85.2\%), Technical and industrial production (10.8\%), Building and construction (5.5\%), Electricity and electronics (5.3\%) (Statistics Norway 2013). In all, the students choose between 12 upper secondary school programmes upon leaving compulsory education. Of these, eight are vocational programmes (Sales and service, Agriculture, Fishing and forestry, Restaurant and food processing, in addition to the five mentioned above). Male students comprise $57 \%$ of the VET students (Statistics Norway 2016). For the VET students, the normative route to a vocational certificate is two years in school and two years in apprenticeship. In reality, however, a greater number male than female VET students transition into training and later vocational certification, and $71 \%$ of apprentices are male (Statistics Norway 2016). Female VET students more often transition into general studies, than male students do.
} 
education however, is that the students 'self-sort' into stereotypically gendered vocational subjects and education programmes (cf. Niemeyer and Colley 2015). In Norway, the educational choice process accentuates young people's autonomy at an important age for gender identity development (Smette 2015, Foskett and Hemsley-Brown 2001). As such, the fact that certain subjects and vocations are coded as stereotypically feminine or masculine may enter into their gender identity development process (Gottfredson 2002) and their selfsocialisation into certain occupations (Heinz 1999).

During secondary schooling years, important gender identification processes take place, and social relationships and experiences are highly formative. Research based on constructivist or gender-relational perspectives has discussed whether single-sex schooling affirms or breaks stereotypical gender constructions (J. Jackson 2010; Younger and Warrington 2002). In her review of single-sex education research, Smyth sees research potential in exploring national gender regimes and their possible relationship to gender (re)construction within single-sex schooling (Smyth 2010, 53). From this perspective, there is particular interest in young female students' social relationships in Norwegian single-sex classrooms - a country where gender equity is high on the agenda - and the way stereotypical femininity is countered or reaffirmed in female peer interaction. A vocational education setting, where gender constructions relate to constructions of subjects and vocations, could influence these young women's choices of further education and work (Estévez-Abe 2012; Haasler and Gottschall 2015).

This paper aims to analyse young female students' stories about social relationships in allfemale upper secondary VET settings. This study aims to explore how these female students describe relationships, competition, conflicts and community in terms of stereotypical or nonstereotypical femininity. While social psychological perspectives on young people's identity development may offer insight into important social aspects of being young in a school context, the current study focuses on gender discourses, practices and identity from a constructivist perspective on identification processes (Hall 1996). This study considers gender stereotypes and constructions to be potential resources as well as possible constraints for young people's (self-)socialisation in education, in line with such a perspective. However, the study argues that this self-socialisation may also be important for their development and trajectories into young adulthood, as would be suggested by social-psychological perspectives.

The analyses show that this study's female students use negative stereotypically gendered terms to describe their social relationships with classmates, and that aspects other than gender seem to be more important for creating integration and a feeling of commonality and belonging. The first part of this article will review research on single-sex schooling and gendered discourses in education. Following the data and method description, the four results sections will focus on social relationships described by the informants, including 
supportive relationships, competition and conflicts. This study will then turn to the question of whether the female informants see their gender as important for group identification.

\section{Qualitative studies on single-sex schooling and gendered discourses in education}

From one perspective, single-sex schooling has been initiated as a means to counter boys' underachievement (Younger and Warrington 2006), and from another, to benefit female students' schooling and psychosocial development (Gilligan, Lyons, and Hanmer 1990). These arguments diverge in their understanding of the relationship between schooling and gender stereotypical behaviour. In the 'boys' underachievement' setting, single-sex schooling is seen as allowing teaching efforts to align with what was described as boys' learning styles, thus affirming gender stereotypes (Younger and Warrington 2006). Gilligan et al. (1990), on the other hand, argued that single-sex schooling allows female students to voice their aspirations and develop stronger autonomy than they would in a co-educational setting, thus breaking with gender stereotypes. In their literature review, Mael et al. (2005) found little evidence for the latter argument, as some studies found that single-sex schooling affects self-concept and locus of control, while the opposite was true for self-esteem. However, Mael et al. (2005) claim that female students in single-sex classrooms could be expected to tell stories of positive classroom cultures with 'the potential to increase aspiration levels and open new opportunities for students' (85).

Critics of same-sex education claim that pro-single-sex education arguments rest on 'the unfounded assumption that humans come in two varieties - male and female' (J. Jackson $2010,227)$. A parallel critique is found in literature pertaining to the 'underachieving boys' discourse (Skelton 2001), in which gender group generalisations are seen as being based on essentialist assumptions that disguise huge variations in how male and female students are 'doing gender'. As Smyth (2010) points out, single-sex schooling takes place in very different contexts. Female students in Norway's female-dominated vocational education could differ in their way of 'doing gender' from, for instance, the predominantly middle-class student body of selective all-girls Catholic schools (cf Gilligan, Lyons and Hanmer 1990). Additionally, the members within the group of female students may vary greatly. Qualitative studies may offer a greater understanding of diversity in gender constructions generally and in VET, and how young people use or counter stereotypically feminine ideals and behaviour in a school setting.

In her book Gender Play (1993, 90-95), Barrie Thorne describes how research on gender in schools has contributed to discourses that describe school gender cultures as 'separate and different'. In these descriptions, female students were found to be dyadic, private, collaborative and focused on relationships and intimacy. Consequently, the constructions of female school cultures emphasised connection, solidarity and commonality - an 'egalitarian ethos' where conflicts were not expressed directly. Ambjörnsson (2004) shows how Sweden's female students are expected to be soft, caring, tolerant, controlled and other-oriented. Her 
'S-girls' (Social sciences programme, academically oriented) live up to this ideal, constantly negotiating and struggling to fit the mould.

However, both scholars describe behaviour and events that break with these expectations. Thorne's description of the tomboy (1993) and Ambjörnsson's (2004) description of the loud and angry BF-girls (Child care and recreation programme, vocationally oriented) show how female students can break with expectations, counter discourse and shape their own gender role and identity. Thorne warns that the overarching discourses of femininity may skew research and cover up the signs that female students behave counter to expectations, noting that this should be taken seriously in all gender and schooling research. In an article on gendered subjectivities in the choice and transition to vocational education, Lappalainen, Mietola and Lahelma (2012) assert that ideas of different social cultures exist in female- and male-dominated work and education fields. However, their data on 'duplicity and gossiping'which may be far from the egalitarian ethos Thorne's review described as feminine (1993)also demonstrated features of the strongly female-dominated VET field of social and healthcare education. The authors interpret this as aligning with stereotypically gendered expectations. Thus, gendered narratives might not be as univocally 'feminine' or counterstereotypical as assumed; gender stereotypes may shape behaviour, represent emotions and inform the stories of female students in all-female classes in different ways.

Learning and socialisation in education shapes current and future identities related to gender and career. The literature reviewed above inspires this study to analyse the way gender discourse and stereotypes are represented in female VET students' stories, based on the assumption that how femininity is made relevant in a school class influences learning and socialisation, as well as students' future identities. This study analyses the narratives of school class relationships. Are relationships described as supportive and caring paralleling the stereotypical constructions of female school cultures described by Thorne (1993)? If the stories describe competition and conflict, are they described in ways that break from the female gender stereotypes? Another question is whether a school class of (nearly) only female students creates a gender identity bond or if other aspects of their identity are of equal importance. In addition to focusing on female students in VET, this article sheds light on processes of identity, belonging and support in a gender-segregated vocational education setting.

\section{Data and methods}

This article is based on educational life-story interviews conducted in 2013 with female students who completed a vocational upper secondary study programme with at least $85 \%$ female students. These interviews originate from a larger body of interviews with VET students in Oslo that were conducted as part of the study Safety-VET: Qualification and social inclusion in VET, which is a study on VET drop-out and completion processes, focusing on the 
development of learner identities, social inclusion and competence. In this study, male and female VET students were recruited through various channels.

For this article's purposes, the female respondents in gender-segregated VET were analysed. The 13 female VET students included in the Safety-VET project were all born and raised in Oslo and were pulled from the Longitudinal Oslo Youth Study 2006-2010 sample (Hegna 2014). These informants had previously consented to being contacted for this purpose and were at the age of expected VET completion (21 years old). Two of the respondents had not followed a predominately female study programme and were not included. Two informants who had not completed upper secondary education were included in the analysis due to their experience with all-female education. Six informants initially studied in the Healthcare, childhood and youth development study programme (HCYD), while five informants studied in the Design, arts and crafts programme (DAC). Four of the six HCYD students had parents in working-class positions, while of the five DAC students, three were from middle-class backgrounds. Of the 11, five had two Norwegian-born parents, three had an immigrant family background and three were of mixed origin.

The interviews took the form of educational life stories up to the age of 21, starting with the first day at school and following the interviewee's school biography-their learning experiences, their classmate and teacher experiences, the transitions between school levels and their parents' role in their education. This method was selected to access narratives of the processes and as well as development over time in their education, reflecting the combination of the two perspectives of the study. The interviews are thus seen as recollections and re-constructions of the informants' schooling, and their stories must be understood and analysed as such. In their narratives, gendered constructions of relationships and identities are found. In turn, these understandings have a bearing on the young women's understanding of themselves and their role in class and in education, which can add to the analysis of social-psychological processes of belonging and development.

The interview section that touches on the social relations and VET class experiences was introduced with an open question that asked the students to talk about their class. Only after their initial description did the interviewer probe into the particular situation of the all-female environment. Most informants mentioned before the probe was introduced that the female student dominance in their class was characteristic of their vocational education. All but two interviews were conducted by a research assistant; of the remaining two, one was conducted by the author and one was conducted together. 
All interviews were fully transcribed and coded using Nvivo $10^{3}$. All utterances that described social relations and student social interaction were coded. In the initial analysis phase, the analytical themes were related to support, collaboration, conflict, competition, similarity and difference. Stories about the female student dominance in their class characterised the material. Thus, in further thematic analyses, the gendering of the stories and the gendered meanings attached to both these conflicts and to the positive and negative relationships were included. The material presented in this article represents different aspects of their stories, with quotes including 8 of the 11 informants. These were selected to represent the main aspects of social relationships found in the interviews, as well as to exemplify the different ways in which this is described and the roles stereotyped femininity constructions play in their stories.

\section{Social support and encouragement towards completion from female class mates?}

Lisa was the first student interviewed for the project. She was a 21-year-old woman who started her upper secondary education in the DAC study programme five years ago. After one year of general arts, crafts and design studies, she spent one year specialising in interior design before choosing the one-year supplement ${ }^{4}$ to obtain a general education certificate. We asked her about her thinking related to this option:

Interviewer: You make it sound like you were planning to take this supplementary year all from the start. Did you get the feeling during your first year that there were many people in your class that had the same idea at this point?

Lisa: I don't think we talked about it a lot. No ... I don't think so. I don't think most of them were thinking about that then. I think that most of them thought that they would [get to] do the things they wanted after the third year [Of VET]. Interviewer: So for most of them, this was an idea that formed gradually? Lisa: Yes, I think so. And we influenced each other because many people said 'you have to choose the supplementary year to do so and so, and do it with us because then we will be doing it together and it won't be too bad to go another year'. We went into it together. [...] One girl in my class was beginning to stagger, and she started saying 'Naa, I think I'll just quit', and we were in the third grade and all of us said 'It's no use quitting now! We'll get through it and then you'll be done with it rather than having to start all over'. So we tried to get her to understand that you can never escape upper secondary school if you don't complete it. She actually completed the supplementary year with us [after completing VET].

\footnotetext{
${ }^{3}$ Nvivo is software that supports qualitative and mixed methods research, designed to organize, analyse and find insights in unstructured or qualitative data, like interviews and open-ended survey responses.

${ }^{4}$ Students in the Norwegian VET have the opportunity to enrol an additional supplement year after 2--4 years in VET, to take the exams they need to qualify for higher education. Some students plan for this option from the start, others see it as an option manifesting itself during their VET years, while yet others are 'pushed into' it because of a lack of an apprenticeship alternative.
} 
This quote describes a female collective where higher education aspirations spread from those who planned from the start to take the supplementary year to those planning to (hopefully) complete the vocational education and start working in low-skilled jobs-for instance in home decor stores. Lisa also points out how many students have unrealistic expectations about their possibilities in the labour market after completing upper secondary VET. Their wishful thinking receives a hard reality check through other people's (co-students or others) information, and they realise that to get to 'do the things they want' in their working life, they have to study further. This indicates how receiving knowledge about possibilities and occupational information from co-students that you trust can be important for aspiration formation. In addition, this may be seen as an example of how selfunderstandings and gender- and work-related identities are constructed via the influence from others.

This community of students agreed that it would be easier to take the supplementary year if they did it together, supporting the friend that 'staggered' and almost opted out of school during the third year. This supportive class culture echoes Mael et al.'s hypothesis (2005) and exemplifies how an all-female environment could support the development of higher education aspirations, give social support, foster motivation and help spread information about labour market demands. As such, her story could also be said to echo traditional constructions of female school cultures in the emphasis placed on collaboration and solidarity. At the same time, Lisa's story of how the female collective acted on their aspirations to seek higher education and work their way through the theoretical supplement is also a story about strong will and fighting spirit. In this way, the female students opt out of a vocational route, which often provides low pay and few career opportunities, to seek higher education. For Lisa, with her middle-class background and later studies in art history at the university, this may not have been such a big step, but for others in her group, this could have been quite ambitious. Thus, at play in her story is not univocally traditional constructions of gender.

However, more examples of particularly supportive environments and positive school climate were not found when analysing the following interviews; instead, those interviews contained an overwhelming body of stories of open, aggressive conflicts and classroom competition. It became evident that the informants were not only describing events and experiences that were riddled with this, but that they were also drawing upon a general body of discourse on female conflicts that influenced the way they experienced and described these conflicts. 


\section{Competition in the classroom}

In the interview with Christine, she was asked if many of her friends from lower secondary school followed her to her upper secondary school. She answered by talking about the special case of being in a class of 27 female students. She described herself as a girl who only 'clicks' with a few other girls, while with boys 'it is a bit more relaxed atmosphere'. With girls however:

Christine: ... I don't know how to explain it, but it is so tiring. People mind so much, all the time, about all sorts of things, about how you look and what you are doing. It is like a competition, in a different way. Clever girls who want to be the best, and you get a bit bitchy at times. [...] I think maybe it is about ... that it is easier to not like other girls, for girls. Because you maybe compete about different stuff-like unconsciously, without knowing, but it is so easy to find things about others that you don't like.

Interviewer: You mean about their looks?

Christine: No, more like their behaviour and attitudes and stuff [...] It's very difficult [to explain], but it's a girl thing.

Christine, 21, Norwegian background, middle class, DAC: exhibition design.

Christine grew up in Oslo's affluent west end, with parents employed in positions indicating high cultural capital. In her quote, she describes the sort of competition for status and achievement that other interviews similarly described as going on in several of the femaledominated classrooms. Status hierarchies were very much in play, based on looks, academic performance or skills, coolness, ethnicity and so on. In Christine's story, this is described as a side of the female gender in general: 'it's a girl thing'. However, Susanna, who was also in the DAC programme but who grew up with her working-class mom explains the hierarchy as being the result of one person. As she explained, 'We were all like a big group of girls at first, but then I realised that one of the girls was more like a boss than the rest of us. She started to select/pick out people she didn't like, and the rest of us were supposed to follow her lead'.

Theorists have highlighted how women who break gender norms and stereotypes can be 'punished' by others - women should not be bossy, and if they are, they need to combine domination with softness and 'warmth' to get away with it (Rudman and Glick 2001). While the informants' stories could be interpreted as examples of this 'backlash', this study argues that their stories are more indicative of what adults in school often label and depreciate as 'girl trouble', but which might also characterise the social exclusion processes that often lead to bullying (Søndergaard 2012). Interpreted this way, the stories of competition could be seen as within the discourses of stereotypical feminine 'troublemaking', though also as 'clever' and 'bossy' female students breaking stereotypes. The informants' stories about competition describe the 'bitching' as a strategy for holding each other down or to put themselves in 
front. Heidi's story below clearly illustrates how competition can be perceived as a negative force in a social environment, marginalising some and favouring or supporting others:

Heidi:... some people are just the loudest and want to be the best, and they look down on everyone else. At least when you are like me, a little shy and a bit nerdy and not ... yeah, I didn't dare to speak out too much. People were looking at me like 'Oh, my GOD' (ROLLING EYES). [...] It's no fun to be in a class where you don't know the others in your class. For a whole year you'll just feel like you are in the way (HER EMPHASIS). I just didn't like going to that school. [...]

Interviewer: So that's how you felt ...

Heidi: Not really in the way, because it was my school as well, but I felt that the ones who were the loudest had a stronger right ... I felt that it was their school in a way. Heidi, 21, Norwegian background, working class, DAC: interior design.

In this class, being 'loud' and being 'best' merges in the description of the dominating students, and Heidi describes a school setting where 'quiet' femininities are marginalised. The DAC programme-due to its closeness to possible highbrow cultural activities - may attract more middle-class students than other VET programmes. As a consequence, social-class backgrounds may be made salient in the classroom hierarchies and in the way some feel entitled to 'own' the school (cf Bourdieu and Passeron 1990). While Christine is critical of this behaviour, she attributes it to female students in general, perhaps seeing the processes from an unacknowledged powerful position. Susanna and Heidi, however, recognise how the behaviour is related to female students with power who 'own' the school. Encouraging female students to compete and take risks is important in a gender-equity perspective. In a social support perspective, however, competition in class needs to be 'sound' and not degrading to other students, lifting some students at the expense of others.

\section{Gendered stories of conflicts}

Stories about conflicts are also overwhelmingly present in the stories the young women tell of their upper secondary vocational schooling, with the majority describing negative stories (3) or very negative stories (5) about 'drama', fighting and 'bitching' in class. Some short examples show how these kinds of conflicts during the school year were described:

Susanna: [My class] was more girlish kind of. There was more ... I don't know ... more quarrelling maybe, than there was at lower secondary. We became friends, all of us, but ... you know, girls can be bitchy sometimes. They'll make a lot of snide remarks. So that's what happened. 
Rebecca: There was SO much drama. It was ... (BIG SIGH). Maybe that was part of the reason why I got so fed up. There was so much hassle all the time, and I was so tired. You know, really very girlie stuff. All of a sudden, two people won't talk to each other. And then they are the best of friends again. And then a while later, they'll start a fistfight! I think the situation was very demanding for the teachers and a real dump of gossip for us. (She tells a long story about a conflict). It was like being in hell, and we all stood around yelling at each other (LAUGHS). When I think back now, I think it is really embarrassing. We were all so angry with each other for such a small thing. And there were this kind of unnecessary dramas ALL the time.

Rebecca, 21, Nordic background, working class, HCYD: skin care.

The quotes describe different degrees of conflict, which span from quarrelling, 'girlish' behaviour and snide remarks all the way to 'dump of gossip', 'hell' and fistfights. Describing her class as a 'dump of gossip', for instance, leaves no doubt that this was a negative situation for Rebecca and her class.

In analysing the stories, one particular narrative about female conflicts emerged. The importance of this widely shared discursive level was first noticed in the interview with Lisa, where we probed for her opinion of the all-female class. Lisa's answer revealed that she assumed that we were expecting a certain answer:

Interviewer: How was that? To start in a class with almost all girls? Lisa: At first it was like 'Wow, a lot of girls' and I have usually been more ... I become friends with boys more easily than with girls. But it was no PROBLEM (her intonation). A good environment and none of the DRAMA I thought there would be. Or ... a little drama I guess, but not a whole lot.

Lisa, 21, Norwegian background, middle class, DAC: exhibition design.

In her answer, Lisa starts out with a happy exclamation but quickly works to deny what she must have deduced from our question to be the underlying expectation. In her answer, she seems to play up to a perceived expectation of problems and quickly links these problems to an expected degree of drama in an all-female environment. She also describes her own expectations about foreseen drama. It was later on in the interview that Lisa told the story about support and common aspirations that was quoted above. By asking about single-sex schooling experiences, we cannot rule out that we introduce the problem focus to which she responded. Our question cannot, however, be said to have induced any hints of what these problems may be. 
The use of the word 'drama' draws upon a cultural construction of female conflicts and positions like 'drama queen'. One urban dictionary humorously defines it in the following manner: 'Something women and especially teenage girls thrive on. Consisting of any number of situations that have an easy solution, which would bring a fairly good outcome, but these girls choose another, shitty, bad way to deal with it, again consisting of backstabbing, blackmailing/gossiping/betraying their friends. ${ }^{15}$ This 'definition' of drama exemplifies the stereotypical gendered narratives alive in young people's cultural frame, which our informant's answer could be drawing on.

Several of the stories draw upon a certain set of gendered terms for conflicts and tension. Most obviously 'bitchy', but also 'drama', 'gossip' and the way the conflicts are seen as 'girlish' construct these events as specifically feminine conflicts. In addition, the acts of conflict are described as stereotypically feminine: quarrelling, snide remarks, hassle, gossip, backstabbing and screaming. Third, these terms are very much linked to negative forms of 'feminine' behaviour; 'bitchy' or 'girlish' are associated to immorality and immaturity. The narratives and constructions of feminine conflicts are infused with these cultural constructions, and the young female students' experiences are in turn coloured by and interpreted in light of these constructions. On the one hand then, the yelling and the fistfight could be said to break from the stereotypes of feminine behaviour. On the other hand, the discourse colouring the language used for these conflicts is largely central for stereotypical femininity.

Ambjörnsson (2004), in her study in Sweden, explained how the BF-girls (female students in Child and Leisure VET) described themselves as noisy and crude, making themselves heard in the school corridors. While the middle-class female students dismissed them as 'exaggerated', the BF-girls saw themselves as more true and less phony. Lyng (2004) also describes female students in a Norwegian lower secondary classroom with the term 'wildcat' to portray a female student role where lack of rule compliance and loud behaviour is the mode. Last, but not least, Carolyn Jackson's (2006) 'ladettes' completes the picture. These descriptions of disruptive behaviour and conflicts between female students or between students and school underline how these female students break from femininity and gender stereotypes. By doing so, disruption and conflicts are removed from the available scope of feminine behaviour.

Contrary to the descriptions of Thorne (1993) and Ambjörnsson (2004), this study argues that the animosity in these informant's stories is not described as a break from gendered femininity expectations, but rather as aligned with a stereotypical discourse of 'girl' behaviour. On the one side, characterising the conflicts negatively, like 'bitching' and 'drama', can be interpreted as an example of 'backlash' towards agentic women (Rudman and Glick

\footnotetext{
${ }^{5}$ http://www.urbandictionary.com/define.php?term=drama. Used similarly in Norwegian.
} 
2001). At the same time though, when these young female students interpret their own behaviour in terms of stereotypical femininity, it is hard to see the resistance.

\section{Breaking homogeneity}

Based on the previous paragraphs, one can question the basic assumption of the sameness of and commonality between female students in a single-sex educational setting, as Smyth (2010) mentions in her review. These interviews provide very few stories of these students having much in common or being similar in any way. Many informants-including those who told stories about the extensiveness of drama-instead told stories about the variety of female students in their class. Instead of underlining similarity, they mentioned diversity, social cliques, cultural differences and life style differences:

Tina: We were all very different from each other. [...] It was quite OK during class, everybody was laughing and passed paper notes to each other in class, I mean. Everybody was chatting. But when the bell rang, we each went in our own direction. [...] And I just think we were a lot of different people in one class-there were no more than two people who were the same type and all the rest were completely different. It was very diverse.

Tina, 21, Norwegian/African background, working class, HCYD: ambulance assistant.

Maria: ... I was bored of the other girls pretty fast. I had NOTHING in common with them. Only with E who is my best friend still. Apart from that, I just thought that it was boring.

Maria, 21, Norwegian/German background, middle class, DAC: interior design.

In several of the stories, dissimilarity is repeatedly underlined. The students are described as being very different from each other. This seems to break from the idea that these students create a unanimous female group with similar traits.

As the students tell their stories of how little they have in common with their classmates, they also break from any expectation that there would be female solidarity among them. Rather, gender loses its importance as a common denominator as they highlight other characteristics to define their friends. In this quote, Jenny describes how the other students were very different from what she was familiar with:

Interviewer: But you said that you had two friends in particular when you were at that school-could you say something about who they were, what they did ...? 
Jenny: Yes, they were ... she was in my class. And they were very different from-at least one of them was-different from the people I was friends with at home. And now she has become a very good friend of my friends, so by now she is just like us (LAUGHS), you know. The other one-she's always been like me.

Jenny, 21, Norwegian background, middle class, HCYD: child care and youth work.

Jenny had friends at home and in school, but they were very different from each other. After her school friend was included in her group of local friends, her school friend became 'just like us'. The importance of friends being 'just like me' is accentuated by the difference they felt to all the others in class.

Some of the interviewees contrast their friendships with male students to the 'drama' of the female students' group, describing male students as more straightforward and easy going. Still, many also tell stories about friendships with other female students in class, often hinting at the importance of being 'just like' their friend. A hint as to which characteristics they consider important for grouping their fellow students as 'similar' or 'dissimilar' lies in the way they describe themselves and the different groups or cliques in class. Some are described as 'the quiet girls' or 'a little nerdy', with others as 'the party girls'. Another dimension for difference relates to music or cultural styles, for instance, describing one group of students as 'others'.

Jenny (above) grew up in the slightly more affluent west end of Oslo but started her upper secondary education in the working-class-dominated east end. Choosing a vocational education and enrolling in an east-end school was an unusual choice for her local lower secondary school peers. Her trouble in reading and achieving good grades, however, narrowed the choices she had available in $10^{\text {th }}$ grade. This caused difficulty for her transition to upper secondary school because the student body was very different from what she was accustomed to:

Jenny: There were two of us, me and one other girl who had Norwegian names, the only ones. I got the feeling that they didn't like me because I had a Norwegian name and ... yes ... because my clothes were a little more expensive maybe. They would say that I was a brat even though I am not. But first impressions are important. I didn't think I was, but I can see that people would think so when they don't know you. I have chosen VET, so I am no brat. It's just, I don't know, maybe they need something to pick on you for, just because they need someone to pick on.

Jenny, 21, Norwegian background, middle class, HCYD: child care and youth work. 
A third position that underscores the lack of importance ascribed to the common denominator of gender can be found in a quote from Lisa, who at the end of the interview denied the relevance of the question all together: 'I think that there were so many other things that were different that it didn't really depend on the number of girls or boys in class. The transition from lower to upper secondary was about so much else ... so many other changes that I don't know if I thought about it really'. In Jenny's case, social class and ethnicity fell together and marked a significant difference between her and her classmates, overriding any gender-based commonalities, if there were any in the first place. In her story, the usual social class hierarchies seem to be turned on their heads, as some ethnic minority students from working-class backgrounds started to bully Jenny on her first day. For Maria and Tina, gender was not seen as an important source of similarity because there were other dimensions to establish the 'just like me'-feeling, as well as there being inseparable differences between the female students, as was the case for Jenny.

\section{Discussion}

The analyses of female VET students' stories about their experiences of social relations in their primarily female-dominated class show that stories of competition, conflicts, hierarchies and differences are more prevalent than stories of commonality, support, belonging and caring. On the surface, this could suggest the conclusion that female VET students in gendersegregated Norwegian education break from stereotypes of typical feminine behaviour in education. However, I argue that the analyses also indicate that the informants' narratives construct these social relationships as stereotypically feminine because of their use of terms such as like drama, bitching, gossip and backstabbing.

The young women in this study relate their conflicts to specific 'feminine' traits, drawing upon essentialist notions of the female nature. On the other hand, they place strong emphasis on the differences between the students in class and how they needed a friend that was just like them. These demarcations were based in different styles, cultural interests, ethnicity and social class, and these were considered more important for signifying difference than gender was for signifying similarity and commonality. Put another way, gender was not the only important dimension the students used to identify with others in the class. The foundation for belonging was the ever-returning need of teenagers to have friends 'just like me' in adolescence. Classic descriptions of adolescent society (Coleman 1961) and the life crisis of adolescent identity confusion (Erikson [1968] 1994) reveal that an important task in adolescence is the formation of meaningful relationships and the development of a sense of self and identity through social interaction. By doing this, the adolescents' perspective of importance shifts from being similar in early adolescence to being unique in the late teens, according to Erikson ([1968] 1994). Upon reflection of their past school years, the students put a great deal of emphasis on both difference and similarity in describing the structures of their almost uni-gendered school social environment. Thus, female gender as a broad social category does not contribute to identification in itself. 
Discourses of femininity and conflict, as well as forms of 'feminine' practice, may offer identity and community to some, but they can marginalise others. The patterns this study identified may also be found in other all-female school contexts, or even in groups of female students in co-educational contexts. Nevertheless, this finding breaks from a major underlying notion of the positive effects of single-sex schooling, namely, that putting many female students in the same class will result in a supportive climate that is symptomatic for what these female students have in common - some essential female quality that will be accentuated by bringing them together. It also underlines the need for theories focusing on the social dimensions of learning to reflect important questions of power, hierarchies, selection and exclusion among students (Evans and Niemeyer 2004, 9-10).

Within feminist perspectives, researchers have highlighted how negative sanctions on female aggressiveness and competition also serve to police the limits of accepted feminine behaviour (Brown and Chesney-Lind 2005). In the female students' talk, it is obvious from the negative terms they use to describe conflicts and competition in the classroom that they frame these conflicts as both stereotypically feminine and illegitimate at the same time. Leaving the discursive level aside for a moment, however, it is also apparent that these conflicts and the competition between the female students have real, negative consequences. For some of the interviewees in this study, the conflicts were on the verge of harassment and bullying. Schott and Søndergaard (2014) describe a new perspective on bullying as a relational phenomenon; rather than the bully being defined by some innate aggressive quality, the cause of bullying should be sought in the social relationships and hierarchies of students. In the VET classrooms represented in the female students' stories, intersecting hierarchies of social class, ethnicity and school 'cleverness' seemed to underline the conflicts behind their classmates' bids for power and popularity.

A limitation of this study is that we do not have the stories of the female students who quit their VET education. Upon reflection, the 21-year-old students were quick to point to the 'drama' of an all-female class as characteristic of their VET education. This may in part have been prompted by our questions about this aspect of VET, but at the same time this indicates the commonality of these discourses of stereotypical femininity in school. In the students' hindsight, this is constructed as partly a negative memory.

\section{Concluding remarks}

The informants represent a cohort of female students in Norway starting upper secondary VET in 2007, in which only $23 \%$ completed a trade certificate and $37 \%$ completed a higher education admission certificate (Vibe et al. 2012). Apart from one of the interviewees, all the female students in this study represent the group of female VET students who managed to complete their education with a VET or higher education admission certificate. As such, these informants represent some of the 'winners' of the Norwegian VET system. Even so, their 
stories tell of numerous negative relations and persistent lack of belonging, and are sometimes ripe with the 'resilience of the survivors' (Evans 2006; 401). One of this study's findings is that grouping female VET students together does not contribute to the sense of belonging and support that has been shown to be of importance for the completion of VET education (see e.g. Elffers et al. 2012). Understanding how VET students' sense of belonging or detachment is affected by the gender segregation of VET study programmes may be relevant to our understanding of the social mechanisms of non-completion of VET education.

Another finding of this study is that stories of competition and conflicts are common. However, these stories show that while this may be seen as a sign that female students in female-dominated classes do break from stereotypes of feminine behaviour, it is worth noting that the female students themselves interpret the behaviour as stereotypically feminine. In the process of identification that takes place during youth, such femininity constructions may play a part. Thus, this research contributes to our knowledge on female VET students by focusing on the often gender-segregated nature of VET as a context for social relationships and important identity development processes. Vocational programmes have been remarkably stable in their gender segregation, which is in contrast to the trend of higher education, and identity theory based explanations for this have been suggested to be particularly importance in VET systems with an early or high degree of tracking as is the case in Norway (Imdorf et al 2015, Reisel et al 2015). The autonomous choice of educational pathways at the age of 15 in Norway leave more room for adolescent gender stereotypical behaviour and self-understanding to play a part in this choice. More research is needed to understand if and how students' gender identity processes in the VET context through these gender stereotypical choices represents a mechanism in education that contributes to later gender segregation in the labour market. 


\section{References}

Ambjörnsson, Fanny. 2004. I en klass för sig : Genus, klass och sexualitet bland gymnasietjejer. Stockholm: Ordfront.

Bourdieu, Pierre, and Jean-Claude Passeron. 1990. Reproduction in Education, Society and Culture. London: Sage.

Brown, Lyn Mikel, and Meda Chesney-Lind. 2005. "Growing up Mean: Covert Aggression and the Policing of Girlhood." In 'Problem' girls: Understanding and Supporting Troubled and Troublesome Girls and young Women, edited by Gwynnedd Lloyd, 74-86. London: Routledge.

Coleman, James S. 1961. The Adolescent Society. New York: Free Press.

Elffers, Louise, Frans J. Oort, and Sjoerd Karsten. 2012. "Making the Connection: The Role of Social and Academic School Experiences in Students' Emotional Engagement with School in Postsecondary Vocational Education. " Learning and Individual Differences, 22 (2): 242-250.

Erikson, Eric Homburg. [1968] 1994. Identity. Youth and Crisis. New York: WW Norton \& Company.

Estévez-Abe, Margarita. 2012. "Gendered Consequences of Vocational Training." In The political economy of collective skill formation, edited by Marius R. Busemeyer and Christine Trampusch, 259-283. Oxford: Oxford University Press.

Evans, Karen. 2006. "Achieving Equity through 'Gender Autonomy': The Challenges for VET Policy and Practice." Journal of Vocational Education and Training 58 (4):393-408.

Evans, Karen, and Beatrix Niemeyer. 2004. "Re-enter and Reconnect--but whose Problem is it?" In Reconnection: Countering Social Exclusion through Situated Learning, edited by Karen Evans and Beatrix Niemeyer, 1-28. Amsterdam: Springer.

Foskett, Nicholas, and Jane Hemsley-Brown. 2001. Choosing Futures: Young People's Decision-Making in Education, Training, and Careers Markets. London: RoutledgeFalmer.

Gilligan, Carol, Nona Lyons, and Trudy J Hanmer. 1990. Making Connections: The Relational Worlds of Adolescent Girls at Emma Willard School. Cambridge, MA: Harvard University Press.

Gottfredson, Linda S. 2002. "Gottfredson's Theory of Circumscription, Compromise and SelfCreation." In Career Choice and Development, edited by Duane Brown, 85-148. New York: John Wiley \& Sons.

Haasler, Simone R., and Karin Gottschall. 2015. "Still a Perfect Model? The Gender Impact of Vocational Training in Germany." Journal of Vocational Education \& Training 67 (1):78-92. doi: 10.1080/13636820.2014.922118.

Hall, Stuart. 1996. "Introduction. Who needs 'Identity'?" In Questions of Cultural Identity, edited by Stuart Hall and Paul du Gay, 1-17. London; SAGE publications.

Hegna, Kristinn. 2014. "Changing Educational Aspirations in the Choice of and Transition to Postcompulsory Schooling-a Three-wave Longitudinal Study of Oslo Youth." Journal of Youth Studies 17 (5): 592-613.

Heinz, Walter R. 1999. "Job-Entry Patterns in a Life-Course Perspective." In From education to work: Cross-national perspectives, edited by Walter Heinz, 214-231. Cambridge: Cambridge University Press.

Imdorf, Christian, Kristinn Hegna, Verena Eberhard, and Pierre Doray. 2015. "Educational Systems and Gender Segregation in Education: A three Country Comparison of Germany, Norway and Canada." In Gender Segregation in Vocational Education, edited by Christian Imdorf, Kristinn Hegna and Liza Reisel, 83-122. (Comparative Social Research, volume 31).

Jackson, Carolyn. 2006. Lads and Ladettes in School. Gender and a Fear of Failure. Maidenhead: Open University Press.

Jackson, Janna. 2010. "'Dangerous Presumptions': how Single-sex Schooling Reifies False Notions of Sex, Gender, and Sexuality." Gender and Education 22 (2):227-238.

Lappalainen, Sirpa, Reetta Mietola, and Elina Lahelma. 2012. "Gendered Divisions on Classed Routes to Vocational Education." Gender and Education 25 (2):189-205. doi: 10.1080/09540253.2012.740445. 
Lyng, Selma Therese. 2004. Være eller lære. Om elevroller, identitet og læring i ungdomsskolen. Oslo: Universitetsforlaget.

Mael, F., A. Alonso, D. Gibson, K. Rogers, and M Smith. 2005. Single-Sex Versus Coeducational Schooling: A Systematic Review. Washington: U.S. Department of Education. Office of Planning, Evaluation and Policy Development, Policy and Program Studies Service.

Markussen, Eifred. 2016. "Forskjell på folk!" In De frafalne. Om frafall i videregående opplæring, edited by Kaja Reegård and Jon Rogstad, 22-61. Oslo: Gyldendal Akademisk.

Ministry of Education. 1998. The Education Act. Act of 17 July 1974 no. 55 relating to Primary and Secondary Education and Training.

Ministry of Education. 1998. The Education Act. Act of 17 July 1998 no. 61 relating to Primary and Secondary Education and Training.

Niemeyer, Beatrix, and Helen Colley. 2015. "Why do We Need (another) Special Issue on Gender and VET?" Journal of Vocational Education \& Training 67 (1):1-10.

Osterman, Karen F. 2000. "Students' Need for Belonging in the School Community." Review of Educational Research 70 (3):323-367.

Reisel, Liza, Kristinn Hegna, and Christian Imdorf. 2015. "Gender Segregation in Vocational Education: Introduction." In Gender Segregation in Vocational Education, edited by Christian Imdorf, Kristinn Hegna and Liza Reisel, 1-22. (Comparative Social Research, volume 31).

Rudman, Laurie A, and Peter Glick. 2001. "Prescriptive Gender Stereotypes and Backlash toward Agentic Women." Journal of Social Issues 57 (4):743-762.

Schott, Robin May, and Dorte Marie Søndergaard, eds. 2014. School Bullying. New Theories in Context. Cambridge: Cambridge University Press.

Skelton, Christine. 2001. Schooling the Boys: Masculinities and Primary Education. Educating Boys, Learning Gender. Florence: Taylor \& Francis Inc.

Smette, Ingrid. 2015. "The Final Year. An Anthropological Study of Community in Two Secondary Schools in Oslo, Norway." PhD diss., Department of Social Anthropology, University of Oslo.

Smyth, Emer. 2010. "Single-sex Education: What does Research Tell Us?" Revue française de pédagogie. Recherches en éducation (171):47-55.

Statistics Norway. 2013. "Videregående opplæring og annen videregående utdanning, 2013." Statistics Norway Accessed 01.07.2016.

https://www.ssb.no/utdanning/statistikker/vgu/aar/2014-0612 ?fane=tabell\&sort=nummer\&tabell=179486.

Statistics Norway. 2016. "Videregående opplæring og annen videregående utdanning, 2015." Statistics Norway Accessed 29.09.2016. https://www.ssb.no/utdanning/statistikker/vgu

Søndergaard, Dorte Marie. 2012. "Bullying and Social Exclusion Anxiety in Schools." British Journal of Sociology of Education 33 (3):355-372.

Thorne, Barrie. 1993. Gender Play: Girls and Boys in School. New Bunswick: Rutgers University Press. Vibe, Nils, Mari Wigum Frøseth, Elisabeth Hovdhaugen, and Eifred Markussen. 2012. Strukturer og konjunkturer. Evaluering av Kunnskapsløftet. Sluttrapport fra prosjektet 'Tilbudsstruktur, gjennomføring og kompetanseoppnåelse i videregående opplæring'. In NIFU report 26/2012. Oslo: NIFU.

Wiseman, Alexander W. 2008. "A Culture of (In)equality? A Cross-national Study of Gender Parity and Gender Segregation in National School Systems." Research in Comparative and International Education 3 (2):179-201.

Younger, Michael Robert, and Molly Warrington. 2006. "Would Harry and Hermione have Done Better in Single-sex Classes? A Review of Single-sex Teaching in Co-educational Secondary Schools in the United Kingdom." American Educational Research Journal 43 (4):579-620.

Younger, Mike, and Molly Warrington. 2002. "Single-sex Teaching in a Co-educational Comprehensive School in England: An Evaluation based upon Students' Performance and Classroom Interactions." British Educational Research Journal 28 (3):353-374. 
